\title{
Novel modification by L/F-tRNA-protein transferase (LFTR) generates a Leu/N-degron ligand in Escherichia coli.
}

2 Ralf D. Ottofuelling ${ }^{1, \dagger}$, Robert L. Ninnis ${ }^{1, \S}$, Kaye N. Truscott ${ }^{1,2 *}$ \& David A. Dougan ${ }^{1,2^{*}}$

$3{ }^{1}$ Department of Biochemistry and Genetics, La Trobe Institute for Molecular Science, La Trobe

4 University, Melbourne, Victoria, 3086, Australia.

$5 \quad{ }^{2}$ These authors have contributed equally to this work and share senior authorship

6 * Correspondence:

7 David A. Dougan

8 d.dougan@latrobe.edu.au

9 Kaye N. Truscott

10 k.truscott@latrobe.edu.au

$11 \dagger^{\dagger}$ Present address: CSL, Melbourne, Vic., 3052, Australia.

12 §Present address: Trajan, Melbourne, Vic., 3134, Australia.

15 Keywords: Leu/N-degron, N-degron, protein modification, ClpS, adaptor, AAA+ protease, 16 bacterial proteostasis. (Min.5-Max. 8) 


\section{ABSTRACT}

The N-degron pathways are a set of proteolytic systems that relate the half-life of a protein to its Nterminal (Nt) residue. In Escherchia coli the principal N-degron pathway is known as the Leu/Ndegron pathway of which an Nt Leu is a key feature of the degron. Although the physiological role of the Leu/N-degron pathway is currently unclear, many of the components of the pathway are well defined. Proteins degraded by this pathway contain an $\mathrm{Nt}$ degradation signal (N-degron) composed of an Nt primary destabilizing $\left(\mathrm{N}_{\mathrm{d} 1}\right)$ residue (Leu, Phe, Trp or Tyr) and an unstructured region which generally contains a hydrophobic element. Most N-degrons are generated from a pro-N-degron, either by endoproteolytic cleavage, or by enzymatic attachment of a $\mathrm{N}_{\mathrm{d} 1}$ residue (Leu or Phe) to the $\mathrm{N}$-terminus of a protein (or protein fragment) by the enzyme Leu/Phe tRNA protein transferase (LFTR) in a non-ribosomal manner. Regardless of the mode of generation, all Leu/N-degrons are recognized by $\mathrm{ClpS}$ and delivered to the ClpAP protease for degradation. To date, only two physiological Leu/N-degron bearing substrates have been verified, one of which (PATase) is modified by LFTR. In this study, we have examined the substrate proteome of LFTR during stationary phase. From this analysis, we have identified several additional physiological Leu/Ndegron ligands, including AldB, which is modified by a previously undescribed activity of LFTR. Importantly, the novel specificity of LFTR was confirmed in vitro, using a range of model proteins. Our data shows that processing of the Nt-Met of AldB generates a novel substrate for LFTR. Importantly, the LFTR-dependent modification of $\mathrm{T}_{2}$-AldB is essential for its turnover by ClpAPS, in vitro. To further examine the acceptor specificity of LFTR, we performed a systematic analysis using a series of peptide arrays. These data reveal that the identity of the second residue modulates substrate conjugation with positively charged residues being favored and negatively charged and aromatic residues being disfavored. Collectively, these findings extend our understanding of LFTR specificity and the Leu/N-degron pathway in E. coli. 
$\mathrm{N}$-terminal Thr is a novel secondary destabilizing residue

\section{INTRODUCTION}

Protein degradation is an essential cellular process that is responsible for the removal of unwanted or damaged proteins. Given the irreversible nature this process, the recognition of a protein substrate is generally tightly controlled, not only by the conditional exposure of a degron, but also by the regulated activation of distinct proteolytic machines that are responsible for recognition (and removal) of these proteins. In the bacterial cytosol, this process is performed by a handful of ATPdependent machines, which are commonly referred to as AAA+ (ㅅTPase associated with a variety of cellular activities) proteases (Striebel et al., 2009;Sauer and Baker, 2011;Gur et al., 2013;Alhuwaider and Dougan, 2017). These machines are generally composed of two components: an ATP-dependent unfoldase component belonging to the AAA+ superfamily (Neuwald et al., 1999;Ogura and Wilkinson, 2001), which is responsible for recognition and unfolding of the substrate and a specialized peptidase component responsible for destruction of the unfolded protein into short peptides. In a handful of cases, these machines also employ an additional component, commonly known as adaptor proteins, for the recognition of specific degrons (Dougan et al., 2002a;Kirstein et al., 2009;Mahmoud and Chien, 2018).

Degrons are generally short linear motifs ( $1-12$ residues long) that serve as degradation signals. Given the main determinant of these signals is located at either the $\mathrm{N}$ - or C-terminus of a protein, they are commonly termed N- or C-degrons, respectively (Tobias et al., 1991;Tu et al., 1995;Keiler et al., 1996;Flynn et al., 2003;Erbse et al., 2006;Ninnis et al., 2009;Gao et al., 2019; Varshavsky, 2019; Timms and Koren, 2020). Although some degrons are constantly exposed and hence constitutively degraded, most degrons are generated conditionally, through the activation or exposure of a pro-degron (Hwang et al., 2010;Kim et al., 2014; Chen et al., 2017; Lucas and Ciulli, 2017;Dougan and Varshavsky, 2018;Varshavsky, 2019). The molecular components responsible for the generation, recognition and removal of a degron are defined by a degron pathway (Varshavsky, 2019; Timms and Koren, 2020). Currently, two N-degron pathways have been described in bacteria; the fMet/N-degron pathway for the co-translational removal of misfolded nascent polypeptides that retain their formyl group (Piatkov et al., 2015) and the Leu/N-degron pathway (Varshavsky, 2019), formerly the N-end rule pathway (Tobias et al., 1991), which is the canonical N-degron pathway in bacteria. Although the physiological role of the Leu/N-degron pathway in E. coli remains poorly understood, many of the molecular components are well defined. In the bacterial Leu/N-degron pathway, individual residues located at the N-terminus of a protein, can be considered either 
stabilizing or destabilizing (Tobias et al., 1991;Varshavsky, 2011). Similar to the Eukaryotic Ndegron pathways, $\mathrm{Nt}$ destabilizing $\left(\mathrm{N}_{\mathrm{d}}\right)$ of the bacterial Leu/N-degron pathway are hierarchic $(\mathrm{Mogk}$ et al., 2007; Varshavsky, 2011;Dougan et al., 2012;Tasaki et al., 2012;Gibbs et al., 2014;Dissmeyer et al., 2018;Bouchnak and van Wijk, 2019; Varshavsky, 2019), composed of primary destabilizing $\left(\mathrm{N}_{\mathrm{d} 1}\right)$ residues (Leu, Phe, Tyr and Trp) and secondary destabilizing $\left(\mathrm{N}_{\mathrm{d} 2}\right)$ residues. While $\mathrm{N}_{\mathrm{d} 1}$ residues are recognized directly by $\mathrm{ClpS}$, the N-recognin (N-terminal recognition component) of the pathway (Erbse et al., 2006;Wang et al., 2008b;Schuenemann et al., 2009), $\mathrm{N}_{\mathrm{d} 2}$ residues require specific modification to generate a destabilizing activity (i.e. attachment of a $\mathrm{N}_{\mathrm{d} 1}$ residue, e.g. Leu or Phe). To date, a total of five different $\mathrm{N}_{\mathrm{d} 2}$ residues have been identified in bacteria, three (Arg, Lys and in a single case, Met) in E. coli (Tobias et al., 1991;Shrader et al., 1993;Ninnis et al., 2009; Dougan et al., 2012) and four (Arg, Lys, Asp and Glu) in Vibrio vulnificus (Graciet et al., 2006). The modification of proteins bearing an $\mathrm{N}_{\mathrm{d} 2}$ residue is performed by two separate enzymes, the bacterial protein transferase (Bpt) is responsible for the Nt-leucylation of proteins bearing the $\mathrm{N}_{\mathrm{d} 2}$ residues (Asp or Glu) in Vibrio vulnificus (Graciet et al., 2006). While in E. coli, Leu/Phe-tRNA-protein transferase (L/F-transferase, here referred to as LFTR) is responsible for the conjugation of Leu or Phe to proteins bearing the $\mathrm{N}_{\mathrm{d} 2}$ residue (Arg, Lys or Met) (Tobias et al., 1991; Shrader et al., 1993;Ninnis et al., 2009;Schmidt et al., 2009). Based on the crystal structure, LFTR contains two pockets, one for the recognition of the acceptor (or substrate) and the other for recognition of the donor tRNA bearing the amino acid for conjugation to the substrate (Suto et al., 2006; Watanabe et al., 2007). While the donor specificity of LFTR in vitro includes Leu-tRNA, Phe-tRNA and to a lesser extent Met-tRNA (Kaji et al., 1963;Leibowitz and Soffer, 1970;Scarpulla et al., 1976), in vivo studies suggest that leucylation is the dominant type of conjugation (Shrader et al., 1993). Similarly, although the acceptor specificity of LFTR, originally defined using model substrates, was proposed to be restricted to the Nt amino acids Arg, Lys and to a lesser extent His (Soffer, 1973; Tobias et al., 1991), the identification of Putrescine aminotransferase (PATase, also known as PatA) as the first physiological substrate of LFTR showed that Met can also serve as an acceptor for this enzyme (Ninnis et al., 2009; Schmidt et al., 2009). This finding led to speculation that the acceptor specificity of LFTR may be broader than initially defined using model substrates (Tobias et al., 1991;Ninnis et al., 2009; Dougan et al., 2010). Therefore, in order to further investigate the acceptor specificity of LFTR we sought to identify the physiological substrates of this enzyme. 
106 isolated from $\triangle \operatorname{clp} A E$. coli, facilitated the identification of eight putative LFTR Leu/N-degron

107 ligands. Three proteins (AldB, AccD and SufD) were verified, using specific antisera, as LFTR-

108 dependent ClpS interacting proteins. The ClpAP-mediated ex vivo turnover of these proteins, was not

109 only dependent on the presence of ClpS but also the activity of LFTR. Significantly, the presence of

110 a non-ribosomal primary destabilizing residue (Leu) was confirmed by N-terminal sequencing of two

111 ligands (AldB and AccD), and the ClpS-dependent turnover of these proteins was also verified using

112 purified components. Unexpectedly, a primary destabilizing residue (Leu) was attached to an Nt Thr

113 on AldB, which identifies MetAP is an integral component of the Leu/N-degron pathway.

114 Furthermore, based on the identification of $\mathrm{LT}_{2} \mathrm{AldB}$ as a novel N-degron ligand, we systematically

115 re-examined the in vitro specificity of LFTR using peptide-based arrays. Taken together, our data

116 show that the recognition of $\mathrm{N}_{\mathrm{d} 2}$ residues by LFTR is broader than previously proposed and the

117 specificity of LFTR is clearly influenced by residues immediately downstream of the $\mathrm{N}_{\mathrm{d} 2}$ residue of

118 the acceptor protein. Finally, based on our identification of this novel ligand, we speculate that

119 MetAP cleavage of other proteins bearing the Nt sequence, MTN may also be compatible with the

120 generation of additional N-degron ligands (under different conditions). From this bioinformatic

121 analysis, we identified 12 cytosolic proteins in $E$. coli with the Nt sequence MTN, six of which are

122 (at least partially) cleaved by MetAP and one (BarA) is a putative ClpA-interacting protein (Butland

123 et al., 2005;Rajagopala et al., 2014;Bienvenut et al., 2015) and hence may represent an additional

124 Leu/N-degron substrate in E. coli.

\section{MATERIALS AND METHODS}

\section{Strains, proteins, protein analysis and antibodies}

127 E. coli knockout strains $\triangle c l p A$ (JW0866) and $\Delta a a t$ (JW0868), were grown at $37{ }^{\circ} \mathrm{C}$ for $26 \mathrm{~h}$ in LB 128 media supplemented with $50 \mathrm{mg} / \mathrm{ml}$ kanamycin, as described in Ninnis et al., (2009). ClpA, ClpP and 129 ClpS (wild-type and mutant) were expressed in E. coli and purified as described previously (Dougan 130 et al., 2002b). LFTR was expressed and purified as described in Ninnis et al., (2009). Leu/N-degron 131 substrates (and controls): SufD, K ${ }_{24}$ SufD, LK ${ }_{24}$ SufD AccD, K ${ }_{16}$ AccD, LK ${ }_{16} A_{c c D}, M_{2} A l d B$, $132 \mathrm{~T}_{2} \mathrm{AldB}$ and $\mathrm{LT}_{2} \mathrm{AldB}$, model GFP-fusion proteins: ( $\mathrm{LK}_{16} \mathrm{AccD}_{16-20} \mathrm{GFP}, \mathrm{LK}_{16} \mathrm{AccD}_{16-24} \mathrm{GFP}$, 133 LK $_{16} \mathrm{AccD}_{16-38} \mathrm{GFP}, \mathrm{LK}_{16} \mathrm{AccD}_{16-55} \mathrm{GFP}, \mathrm{MT}_{2} \mathrm{AldB}_{3-11} \mathrm{GFP}, \mathrm{T}_{2} \mathrm{AldB}_{3-11} \mathrm{GFP}$ and $\mathrm{LT}_{2} \mathrm{AldB}_{3-11} \mathrm{GFP}$ ) 134 and model LFTR substrates (and controls): R-PATase, T-PATase FL-PATase and FM-PATase were 135 all generated using the Ub-fusion system (Catanzariti et al., 2004) and purified essentially as 136 described in Ninnis et al., (2009). Coomassie-stained Leu/N-degron substrates were excised from 
2D-SDS-PAGE gels and in-gel proteolytic digestion performed with either trypsin or GluC. Proteins were identified by MS/MS analysis as described in Ninnis et al., (2009). The N-terminal sequence of selected Leu/N-degron ligands was determined from a protein spot excised from a PVDF membrane, subjected to 5 - 7 cycles of automated Edman degradation, using an Applied Biosystems 494 Procise

141 Protein sequencing system.

\section{In vitro transcription}

143 The tRNA genes ( $p h e V$ and $l e u \mathrm{Z}$ ) were amplified with specific primers that included a T7 promoter. 144 Transcription of tRNA ${ }^{\text {pheV }}$ and $\mathrm{tRNA}^{\text {leuZ }}$ was performed with $20 \mathrm{U}$ T7 RNA Polymerase $\left(37^{\circ} \mathrm{C}\right.$ for $14590 \mathrm{~min}$ ) using the Riboprobe ${ }^{\circledR}$ in vitro Transcription System (Promega) essentially as described in 146 the instructions manual. Following transcription, the sample $(10 \mu l)$ was analyzed by gel 147 electrophoresis using a $2 \%(\mathrm{w} / \mathrm{v})$ TAE-agarose gel to estimate the tRNA concentration.

\section{In vitro aminoacyl-transferase assay}

149 Aminoacylation experiments were performed essentially as described (Ninnis et al., 2009), with 150 minor modifications. For aminoacylation, the protein of interest $(5-125$ pmol $)$ was incubated $\left(37^{\circ} \mathrm{C}\right.$ 151 for $8 \mathrm{~min}$ ) in $25 \mu \mathrm{l}$ reaction buffer $\left(50 \mathrm{mM}\right.$ Tris- $\mathrm{HCl} \mathrm{pH} \mathrm{8.0,100} \mathrm{mM} \mathrm{KCl,} 10 \mathrm{mM} \mathrm{Mg}(\mathrm{OAc})_{2}, 1 \mathrm{mM}$ 152 DTT, 2 mM ATP) containing $\sim 1.0 \mu \mathrm{M}$ of either tRNA ${ }^{\mathrm{PheV}}$ or tRNA ${ }^{\mathrm{LeuZ}}, 8.75 \mu \mathrm{M}\left[{ }^{14} \mathrm{C}\right]-\mathrm{Phe} /$ Leu $(18.3$ $153 \mathrm{GBq} / \mathrm{mmol}$ (PerkinElmer), $38.5 \mathrm{U}$ E. coli aminoacyl-tRNA synthetase (Sigma) and $0.18 \mu \mathrm{M}$ 154 Leucyl/Phenylalanyl-tRNA-protein transferase (LFTR). The reaction was stopped by the addition of 155 sample buffer, then separated by $12.5 \%$ Tris-glycine SDS-PAGE. Following separation, proteins were fixed (30\% (v/v) Methanol, $10 \%(\mathrm{v} / \mathrm{v})$ Acetic acid) in the gel for $30 \mathrm{~min}$, then washed for 15 157 min in $\left(30 \%(\mathrm{v} / \mathrm{v})\right.$ Methanol, $2 \%(\mathrm{v} / \mathrm{v})$ Glycerol). After drying the gel $\left(80{ }^{\circ} \mathrm{C}\right.$ for $\left.1.5 \mathrm{~h}\right) \mathrm{using}$ a 158 Model 583 Gel DRYER (Bio-Rad), it was exposed to a Phosphor Screen (GE Healthcare) for 159 between 1 - 4 days and the protein signal visualized using a Typhoon Trio Variable Mode Imager 160 (GE Healthcare).

162 To examine the binding specificity of LFTR, aminoacylation of peptides attached to a cellulose 163 membrane was performed. Peptides, attached to a cellulose membrane through their C-terminus, 164 were synthesized by spot synthesis (JPT Peptide Technologies). The N-terminal peptide sequences 165 were derived from PATase, $\alpha$-casein, $\beta$-galactosidase and AldB (see Supplementary Tables 3, 4 and 1665 for peptide sequences of individual spots). The membrane was washed (three times with 1x PBS) 167 prior to incubation with the reaction components $\left(15 \mathrm{~min}\right.$ at $37{ }^{\circ} \mathrm{C}$, in a glass tube with gentle 
rolling). Prior to exposure of the membrane, the membrane was washed four times with $500 \mu 1$ of $1 \mathrm{x}$ PBS. After air-drying the membrane was exposed to a Phosphor Screen (GE Healthcare) and the signal visualized using a Typhoon Trio Variable Mode Imager (GE Healthcare).

\section{In vitro degradation assay}

173 Unless otherwise stated, in vitro degradation assays were routinely performed in $200 \mu 1$, using ClpAP 174 Buffer (50 mM Tris- $\mathrm{HCl}$ pH 7.5, 300 mM NaCl, $20 \mathrm{mM} \mathrm{MgAc,} 10 \%$ (v/v) Glycerol, $1 \mathrm{mM}$ DTT) containing $\mathrm{ClpA}_{6} \mathrm{P}_{14}(200 \mathrm{nM})$ in the absence or presence of ClpS $(1.2 \mu \mathrm{M})$. All reactions were preincubated (for $1 \mathrm{~min}$ at RT) with ATP $(5 \mathrm{mM})$ to allow ClpAP complex formation, prior to the addition of the substrate. The reaction (performed at $37^{\circ} \mathrm{C}$ ) was initiated upon substrate addition $(0.5$ - $1 \mu \mathrm{M})$. To monitor the turnover of non-fluorescent protein substrates, samples were collected at various time-points (as indicated) and immediately mixed with SDS-PAGE loading buffer. Proteins were then separated by SDS-PAGE and visualized, either by staining with Coomassie Brilliant Blue or by immunodecoration with specific antisera following transfer to a PVDF membrane. An ATPregeneration system (4 mM Phosphoenolpyruvate (Sigma) and $20 \mu \mathrm{g} / \mathrm{ml}$ pyruvate kinase (Sigma)) was included in reactions lasting longer than $60 \mathrm{~min}$. To monitor the turnover of fluorescent substrates (e.g. GFP-tagged protein substrates) GFP fluorescence (excitation wavelength $=400 \mathrm{~nm}$ and emission wavelength $=510 \mathrm{~nm}$ ) was monitored for the indicated times using a Spectramax M5e plate reader (Molecular Device Inc.), essentially as described (Dougan et al., 2002b).

\section{Purification of ClpS interacting proteins}

188 To study N-degron binding, in vitro "pull-down" experiments were performed as described previously (Geissler et al., 2002;Ninnis et al., 2009). Briefly, settled NiNTA-agarose beads (QIAGEN) were equilibrated in Buffer A $(50 \mathrm{mM}$ Tris- $\mathrm{HCl} \mathrm{pH} 8.0,300 \mathrm{mM} \mathrm{NaCl}, 5 \mathrm{mM}$ Imidazole). The bait protein (wild type or mutant $\mathrm{His}_{6}-\mathrm{ClpS}$ or $\mathrm{His}_{10}-\mathrm{ClpS}$ ) was immobilized to the equilibrated beads ( 15 min end-over-end mixing at $4{ }^{\circ} \mathrm{C}$ ) at a ratio of $2 \mu \mathrm{g}$ of bait protein per $1 \mu \mathrm{l}$ of settled beads. The beads were then washed ( 3 x 10 min) with 3 bed volumes (BV) of Buffer B (50 $\mathrm{mM}$ Tris- $\mathrm{HCl} \mathrm{pH} 8.0,300 \mathrm{mM} \mathrm{NaCl}, 20 \mathrm{mM}$ Imidazole) followed by a single wash $\left(10 \mathrm{~min}\right.$ at $\left.4{ }^{\circ} \mathrm{C}\right)$ with end-over-end mixing using $3 \mathrm{BV}$ of Buffer C (20 mM HEPES-KOH pH 7.5, $100 \mathrm{mM} \mathrm{KOAc,} 10$ $\mathrm{mM} \mathrm{Mg}(\mathrm{OAc})_{2}, 10 \%$ (v/v) Glycerol, $10 \mathrm{mM}$ Imidazole, $0.5 \%$ (v/v) Triton X-100). For N-degron 
198 His $_{6}$ - or $\mathrm{His}_{10^{-}} \mathrm{ClpS}$ were incubated $\left(30 \mathrm{~min}\right.$ at $4{ }^{\circ} \mathrm{C}$, with end-over-end mixing) with an equimolar 199 amount of the prey protein. To isolate novel ClpS-interacting proteins, $\sim 1 \mathrm{~g}$ of soluble E. coli cell

200 lysate (in Buffer C supplemented with a cocktail of protease inhibitors (cOmplete, EDTA-free 201 (Roche)), was incubated $\left(30 \mathrm{~min}\right.$ at $\left.4{ }^{\circ} \mathrm{C}\right)$ with immobilized ClpS $(\sim 1 \mathrm{mg})$ with end-over-end mixing.

202 Unbound proteins were removed by centrifugation $\left(300 \mathrm{~g}\right.$ for $5 \mathrm{~min}$ at $4{ }^{\circ} \mathrm{C}$ ) and the slurry containing

203 bound proteins transferred to a $1 \mathrm{ml} \mathrm{MoBiTec}$ column (Molecular Biotechnology). The slurry was washed with $40 \mathrm{BV}$ of Buffer D (Buffer C containing $0.25 \%$ (v/v) Triton X-100), residual buffer was removed by centrifugation $\left(300 \mathrm{~g}\right.$ for $1 \mathrm{~min}$ at $\left.4{ }^{\circ} \mathrm{C}\right)$. Finally, ClpS-interacting proteins were eluted by centrifugation (300 $\mathrm{g}$ for $1 \mathrm{~min}$ at $4{ }^{\circ} \mathrm{C}$ ) with $1 \mathrm{BV}$ of FR-dipeptide $(1 \mathrm{mg} / \mathrm{ml})$ in Buffer C (without Triton X-100). Eluted proteins were analyzed by SDS-PAGE, immunoblotting or 2DPAGE.

\section{D-PAGE}

210 ClpS-interacting proteins (max. $250 \mu \mathrm{g}$ ), recovered by FR dipeptide elution, from an E. coli cell lysate were precipitated with 4 volumes of cold acetone and resuspended in $150 \mu$ l rehydration solution (8 M Urea, $2 \%$ (w/v) CHAPS, $0.5 \%$ (v/v) IPG buffer 4 - 7 or 3 - 10 (Pharmacia), $20 \mathrm{mM}$ DTT, $0.002 \%(w / v)$ Bromophenol blue). Rehydrated protein samples were separated according to their isoelectric point on an Immobiline ${ }^{\circledR}$ DryStrip gel $(13 \mathrm{~cm}$, linear $\mathrm{pH} 4-7$ or 3-10 gradient strip (Pharmacia)) using an Ettan IPGphor II Manifold with cup loading. The samples were loaded towards the anode end of the rehydrated DryStrip gel (in rehydration solution for 10-20 h) and the proteins focused using the following conditions: $100 \mathrm{~V}$ for $0.5 \mathrm{~h}$, from $100 \mathrm{~V}$ to $500 \mathrm{~V}$ over $2 \mathrm{~h}$, from $500 \mathrm{~V}$ to $1,000 \mathrm{~V}$ over $1 \mathrm{~h}$, from 1,000 to $8,000 \mathrm{~V}$ over $3.5 \mathrm{~h}$ and $8,000 \mathrm{~V}$ for $1 \mathrm{~h}$ at $20{ }^{\circ} \mathrm{C}$. The M Urea, $30 \%(\mathrm{v} / \mathrm{v})$ Glycerol, $1 \%(\mathrm{w} / \mathrm{v})$ DTT and $2 \%(\mathrm{w} / \mathrm{v})$ SDS) then in Buffer B (50 mM Tris$\mathrm{HCl}$ pH 8.8, 6 M Urea, 30 \% (v/v) Glycerol, $135 \mathrm{mM}$ Iodoacetamide and $2 \%$ (w/v) SDS), each for Blue staining or immunodecoration after being transferred to PVDF.

\section{RESULTS}

\section{Deletion of aat (encoding LFTR) inhibits docking of specific N-degron ligands to ClpS}


Although there have been significant advances defining the physiological role of the Leu/N-degron pathway in Salmonella (Yeom et al., 2017;Gao et al., 2019; Yeom and Groisman, 2019), our current understanding of this pathway in E. coli is largely derived from in vitro studies using model substrates (Tobias et al., 1991;Shrader et al., 1993;Erbse et al., 2006;Wang et al., 2008b;Kress et al., 2009;Schuenemann et al., 2009;Roman-Hernandez et al., 2011;Varshavsky, 2011;Rivera-Rivera et al., 2014). As a consequence, the physiological substrates of ClpS are largely unknown and the biological function of the pathway is currently unclear (Ninnis et al., 2009;Schmidt et al., 2009; Dougan et al., 2010; Humbard et al., 2013). Previously, we developed an affinity method to isolate and identify physiological Leu/N-degron substrates from E. coli (Ninnis et al., 2009). To help determine, which of the previously identified ligands may be bona fide N-degron substrates of the ClpAPS machinery, we generated antibodies to a selection of ligands and monitored their ClpSdependent turnover by ClpAP ex vivo (Figure 1A and B). From these experiments we identified SufD (of the SufC/D complex), AccD (of the AccA/D complex) and AldB as putative Leu/N-degron substrates. To determine which of the above putative Leu/N-degron substrates are modified by LFTR we isolated Leu/N-degron ligands from $\Delta c l p A$ cells and compared them with the Leu/N-degron ligands from a mutant E. coli strain ( $\triangle a a t$ ) which lacks LFTR (Figure 1C and Supplementary Figure 1). Initially we analyzed the ClpS-interacting proteins by SDS-PAGE (Figure 1C). Consistent with our previous analysis, 30 different proteins were eluted (using the FR dipeptide) from the wild type ClpS column (Figure 1C, compare lanes 4 and 5). This included two highly abundant proteins (Dps at $\sim 17 \mathrm{kDa}$ and PATase at $\sim 50 \mathrm{kDa}$ ), previously identified as natural substrates of the $E$. coli Leu/Ndegron pathway (Ninnis et al., 2009;Schmidt et al., 2009). Next, we used 2D-PAGE to compare the ClpS-interactome isolated from $\Delta c l p A$ and $\Delta a a t$ cells. As a control, we monitored the recovery of PATase, a confirmed LFTR-dependent substrate (Ninnis et al., 2009;Schmidt et al., 2009;Humbard et al., 2013). As expected, and consistent with our previous findings, PATase was absent from the dipeptide eluted fraction derived from $\Delta a a t$ cells (Figure 1C, lane 6 and Supplementary Figure 1B, Spot 3). These data validate the strains used for the isolation of Leu/N-degron substrates and our approach to identify Leu/N-degron substrates that are modified by LFTR. Notably, more than half of the prominent protein spots were essentially unchanged in the two elution profiles (Supplementary Figure 1C, black Spots 9 - 17) suggesting that, under these conditions, the majority of Leu/N-degron ligands are not modified by LFTR. Nevertheless, using this approach we were able to identify nine prominent protein spots (recovered from $\triangle \operatorname{clp} A$ cells) that were absent from the dipeptide eluted 
suggesting that several $\mathrm{N}$-degron ligands are modified by LFTR in vivo. To determine which proteins were modified by LFTR and at which residue this modification occurred, we identified the proteins recovered from $\Delta c l p A$ by Mass Spectrometry and determined the $\mathrm{N}$-terminal sequence of the most prominent spots (Supplementary Figure 1C, dotted red circles, see Supplementary Table 1). From these data, we identified eight LFTR-dependent ligands (see Supplementary Table 1), two of which (AccA and SufC) were excluded as bona fide N-degron substrates, based on the absence of an $\mathrm{N}_{\mathrm{d} 1}$ residue (i.e. the Nt residue of AccA, recovered from the pull-down, was Ser2) or by the lack of ClpAPS-mediated turnover (i.e. although both SufC and SufD were both recovered by pull-down in an LFTR-dependent manner, only SufD was degraded by ClpAPS, ex vivo) (see Figure $1 B$ and C).

Of the remaining six LFTR-dependent ligands, the N-terminal sequence of three (AccD, AldB and proteins (SufD and RsgA) was proposed, based either on the apparent MW of the recovered ligand or $\mathrm{N}$-degron within ClpB.

In the case of SufD, although its interaction with ClpS was dependent on LFTR activity and its $e x$ vivo turnover was ClpAPS-dependent (Figure 1B) we were unable to determine the identity of its $\mathrm{N}$ terminal residue. Therefore, based on the apparent MW of SufD (recovered from the pull-down) we identified a potential processing site and speculated that SufD was processed (by an unknown peptidase) to reveal Lys24 at the N-terminus (i.e. $\mathrm{K}_{24}$-SufD), to which an $\mathrm{N}_{\mathrm{d} 1}$ residue is attached. Consistent with this proposal, recombinant $\mathrm{LK}_{24}$-SufD co-migrated with processed SufD recovered from the pulldown (Supplementary Figure 2A) and was rapidly degraded in vitro by ClpAPS (Supplementary Figure 2B, filled circles and Supplementary Figure 2C). Interestingly, although the post-translational modification of SufD was not essential for its turnover, the type of modification did control the rate of SufD turnover in vitro. For instance, in the absence of endoproteolytic processing, the ClpAP-mediated turnover of SufD was very slow (Supplementary Figure 2B, open triangles). However, following removal of the N-terminal segment, the rate of SufD turnover (i.e. $\mathrm{K}_{24}-\mathrm{SufD}$ ) was enhanced, by 2.5-fold. Notably, the turnover of both SufD and $\mathrm{K}_{24}$-SufD was completely inhibited in the presence of ClpS (Supplementary Figure 2B, filled triangles and filled squares), while in contrast, $\mathrm{LK}_{24}-\mathrm{SufD}$ was rapidly degraded in the presence of ClpS. Indeed, in the presence of ClpS the ClpAP-mediated turnover of SufD was increased 6-fold by its processing and modification (Supplementary Figure 2B, compare open triangles and filled circles). Taken together these in vitro data could suggest that processing of SufD, through activation of the Leu/N-degron pathway, is a 
potential mechanism to fine-tune the rate of SufD turnover in the presence of ClpS and hence control the cellular levels of SufD. However, the physiological conditions that might trigger SufD processing and its conversion into a putative $\mathrm{N}$-degron substrate currently remain unknown.

295 Next, we examine the in vitro turnover of $\mathrm{LK}_{16}-\mathrm{AccD}$ relative to full length AccD (Supplementary Figure 3). Similar to SufD, full length AccD appears to contain a weak ClpA-recognition motif as it is slowly degraded $\left(t_{1 / 2}>4 \mathrm{~h}\right.$ ) by ClpAP in the absence of ClpS (Supplementary Figure 3A, open squares). Interestingly, this recognition motif appears to be located within this first 15 residues of AccD, as removal of these residues prevents its turnover by ClpAP (Supplementary Figure 3A, open circles). In contrast, attachment of an $\mathrm{N}_{\mathrm{d} 1}$ residue to processed AccD ( $\left.\mathrm{LK}_{16} \mathrm{AccD}\right)$ generates a classic Leu/N-degron substrate, which is specifically and rapidly $\left(\mathrm{t}_{1 / 2} \sim 8 \mathrm{~min}\right)$ degraded by ClpAP in the presence of ClpS (Supplementary Figure 3A, filled circles). Given the N-terminal region of AccD (residues 23-50) contains a stable C4-type Zn-finger domain, we were interested to understand how processed AccD is delivered to ClpAP. To do so, we examined the sequence and structure of the AccD C4-type Zn-finger domain. From this analysis we identified a hydrophobic patch on the surface of AccD, composed of two discontinuous hydrophobic sequences (Supplementary Figure 3C). To examine the potential involvement of these sequence elements in substrate delivery to $\mathrm{ClpA}(\mathrm{P})$, we generated a series of GFP-fusion proteins which contained N-terminal segments (of different lengths) derived from $\mathrm{LK}_{16} \mathrm{AccD}$ (see Supplementary Figure $3 \mathrm{~B}$ ). The shortest segment contained only 5 residues (and lacked the first hydrophobic element). The next construct contained 4 additional residues ( 9 in total and included the first hydrophobic sequence, VW). Finally, the longest construct included the entire C4-type Zn-finger domain (and both hydrophobic sequences) while the last construct was intermediate in size but still included both hydrophobic elements. Interestingly,

314 although the shortest construct lacked both hydrophobic elements, some turnover by ClpAPS was still observed (Supplementary Figure 3C, open blue circles), suggesting that a hydrophobic element is not essential for delivery of all $\mathrm{N}$-degron substrates to $\mathrm{ClpA}(\mathrm{P})$. An alternate explanation for this result, may be that a dihydrophobic element (LF) near the N-terminus of GFP can act as surrogate for delivery to ClpAP. Nevertheless, the rate of turnover was dramatically enhanced when the first hydrophobic element (VW) was included in the sequence (Supplementary Figure 3C, open red circles), and the delivery was further improved when both hydrophobic elements were included in the GFP-fusion protein. Collectively, these data suggest that a linker sequence with at least nine residues downstream of the $\mathrm{N}_{\mathrm{d} 1}$ residue is required for efficient delivery to ClpA. Importantly, these data are consistent with previous findings from several groups, showing that the length of the linker region 
324 plays a critical role in substrate handoff to ClpAP (Erbse et al., 2006;Wang et al., 2008a;Ninnis et al., 325 2009).

326 In summary, consistent with the current dogma for the generation of Leu/N-degron substrates in 327 bacteria, both AccD and SufD are generated from a pro-N-degron, via an unknown endopeptidase, 328 which reveals a classic N-terminal secondary destabilizing $\left(\mathrm{N}_{\mathrm{d} 2}\right)$ residue - Lys - (i.e. $\mathrm{K}_{16}$ in AccD and $\mathrm{K}_{24}$ in SufD), to which a primary destabilizing $\left(\mathrm{N}_{\mathrm{d} 1}\right)$ residue ( $\mathrm{L}$ or $\left.\mathrm{F}\right)$ is then attached by LFTR to generate an $\mathrm{N}$-degron ligand (i.e. $\mathrm{LK}_{16}-\mathrm{AccD}$ or $\mathrm{LK}_{24}-\mathrm{SufD}$ ). In contrast to AccD and SufD, the N-

331 degron of AldB is generated by an exopeptidase to remove a single residue, the initiating Met, which

332 exposes Thr2 at the new N-terminus. This activity is consistent with processing by MetAP, at what 333 has been termed a "twilight" residue (Frottin et al., 2006;Bienvenut et al., 2015; Yang et al., 2019).

334 Hence, it appears that MetAP processing of AldB generates a non-canonical substrate $\left(\mathrm{T}_{2}-\mathrm{AldB}\right)$ for 335 attachment of a primary destabilizing residue $(\mathrm{L})$ to produce an $\mathrm{N}$-degron ligand $\left(\mathrm{LT}_{2}-\mathrm{AldB}\right.$ ). 336 Unexpectedly, the conjugation (of Leu or Phe to $\mathrm{T}_{2}$-AldB) was dependent on the activity of LFTR in 337 vivo. Therefore, in order to confirm the potential of this conjugation with respect to N-degron 338 degradation, we first generated a series of recombinant proteins (using the Ub-fusion system, to 339 ensure the identity of the N-terminal residue) and monitored the ClpAP-dependent turnover of these 340 proteins in the absence or presence of ClpS (Figure 2). Consistent with our identification of $\mathrm{LT}_{2^{-}}$ 341 AldB as both a ClpS-ligand and ClpS-dependent substrate of ClpAP ex vivo, recombinant LT $_{2}-\mathrm{AldB}$ 342 was only degraded by ClpAP in the presence of ClpS (Figure 2A, lower panel lanes 8 - 14). In 343 contrast, both unprocessed AldB $\left(\mathrm{MT}_{2}-\mathrm{AldB}\right)$ and MetAP-processed AldB $\left(\mathrm{T}_{2}-\mathrm{AldB}\right)$ were stable 344 both in the presence and absence of ClpS (Figure 2A, upper and middle panels, respectively). 345 Interestingly, similar to AccD and SufD, a compelling hydrophobic element was also absent from the 346 N-terminal region of AldB, therefore to examine if a hydrophobic element was essential for substrate 347 delivery to ClpA, we fused the first 11 residues of X-AldB (where X refers to either MT, T or LT) to 348 GFP (Figure 2B). Consistent with the turnover of authentic $\mathrm{LT}_{2}-\mathrm{AldB}, \mathrm{LT}_{2} \mathrm{AldB}_{3-11} \mathrm{GFP}$ was the 349 only GFP-fusion protein to be degraded by ClpAPS (Figure 2B, black open circles). Collectively 350 these data confirm $\mathrm{LT}_{2}-\mathrm{AldB}$ as an $\mathrm{N}$-degron substrate and demonstrate that delivery of this $\mathrm{N}$ 351 degron substrate to $\mathrm{ClpA}(\mathrm{P})$ can occur in the absence of a "strong" hydrophobic element within the 352 linker region.

353 Having confirmed that $\mathrm{LT}_{2}-\mathrm{AldB}$ is a potential $\mathrm{N}$-degron substrate, we examined the ability of Thr to 354 act as a secondary destabilizing residue for LFTR. Initially as a control, we tested the activity of 355 LFTR using two artificial model substrates (GFP and PATase) bearing a classic secondary 
356 destabilizing residue $(\mathrm{R})$ at the N-terminus (i.e. R- $\beta$ gal $2-11_{-}-\mathrm{GFP}$ and R-PATase). As expected, $\left[{ }^{14} \mathrm{C}\right]-$ 357 Leu was attached to R- $\beta g_{2-11}$-GFP (Supplementary Figure 4A, lane 3) and R-PATase

358 (Supplementary Figure 4B, lane 3). Next, we used PATase as a model protein to examine the ability of N-terminal Thr to act as an acceptor for LFTR. Consistent with our identification of $\mathrm{LT}_{2}$-AldB as a $360 \mathrm{~N}$-degron ligand recovered from $\triangle c l p A$ cells, T-PATase served as an acceptor for the LFTR361 dependent attachment of radiolabeled Leu (Supplementary Figure 4A, lane 2). We then examined the ability of LFTR to catalyze the attachment of $\left[{ }^{14} \mathrm{C}\right]$-Phe to a selection of X-PATase fusion proteins (Supplementary Figure 4B). Consistent with the conjugation of $\left[{ }^{14} \mathrm{C}\right]-\mathrm{Leu},\left[{ }^{14} \mathrm{C}\right]-\mathrm{Phe}$ was also attached to both T- and R-PATase (albeit to a reduced level than $\left[{ }^{14} \mathrm{C}\right]-\mathrm{Leu}$ ), but not to FM-PATase (Supplementary Figure 4B). Finally, we examined the conjugation of $\left[{ }^{14} \mathrm{C}\right]-$ Leu (or $\left[{ }^{14} \mathrm{C}\right]-\mathrm{Phe}$ ) to recombinant $\mathrm{T}_{2}$-AldB, however despite our efforts we were unable to reconstitute this system in vitro. As a result, we speculated that the lack of conjugation to $\mathrm{T}_{2}-\mathrm{AldB}$ may be due to restricted accessibility of the N-terminus of AldB to LFTR, which could serve as a mechanism to regulate its conjugation in vivo. To overcome this potential constraint, we tested the ability of an Nt Thr (in the context of the native AldB sequence) to act as substrate for LFTR, using the X-AldB $3-11$ GFP fusion protein. Importantly, both radiolabeled amino acids $\left(\left[{ }^{14} \mathrm{C}\right]-\mathrm{Leu}\right.$ and $\left.\left[{ }^{14} \mathrm{C}\right]-\mathrm{Phe}\right)$ were conjugated to $\mathrm{T}$ AldB $_{3-11}$ GFP (Figure 2C, lanes 4 and 9), while in contrast neither LT-AldB ${ }_{3-11}$ GFP (Figure 2C, lanes 2 and 7) nor MT-AldB ${ }_{3-11}$ GFP (Figure 2C, lanes 3 and 8) served as an acceptor for the conjugation of either amino acid. Collectively, these data confirm that an N-terminal Thr residue can serve as an acceptor for LFTR and suggests that the acceptor specificity of LFTR is broader than originally proposed (Shrader et al., 1993). Interestingly, both non-canonical LFTR substrates (i.e. PATase and AldB) shared the same downstream residue (N). As such, we speculated that (a) the identity of the second residue (adjacent to the $\mathrm{N}_{\mathrm{d}}$ ) might contribute to LFTR specificity/activity and (b) more specifically, substrates/proteins bearing a non-canonical Nt-residue might exhibit a restricted preference for specific residues in position 2.

381 Therefore, in order to gain a more complete understanding of LFTR acceptor specificity, we examined the LFTR-dependent conjugation of $\left[{ }^{14} \mathrm{C}\right]$-Leu to several libraries of cellulose bound 11mer peptides. Initially, as a control, we examined the conjugation of $\left[{ }^{14} \mathrm{C}\right]$-Leu to 11 -mer peptides derived from the well-established model peptide substrate, casein fragment 90 - 95 (which includes 
$90-95$ also contained the sequence AGSAG at positions 7-11. Initially we examined the specificity using a peptide library arranged in functional groups (Supplementary Figure 5A). As expected, the peptides bearing an Nt basic residue (Arg or Lys) served as an acceptor for LFTR (Supplementary Figure 5A, spots A-35 and A-36). To ensure the observed conjugation specificity was not due to an uneven distribution of reaction components over the membrane, we altered the arrangement of immobilized peptides on the cellulose membrane (Supplementary Figure 5C, spots 44 and 53). Consistent with Supplementary Figure 5A, the activity of LFTR was unchanged by the peptide position on the cellulose membrane (Supplementary Figure 5C). Importantly, even following prolonged exposure of the membrane(s), incorporation of $\left[{ }^{14} \mathrm{C}\right]$-Leu in "negative" peptides spots was not observed. This suggests that low levels of conjugation are likely to represent actual LFTRmediated conjugation. Next, we examined the specificity of the residue downstream of $\mathrm{N}_{\mathrm{d} 2}$, while maintaining Arg at the N-terminus of the casein peptide (Figure 3A and Supplementary Figure 6) or a peptide derived from the model protein $\beta$-gal (Supplementary Figure 7). Consistent with the idea that the residue at position 2 of the substrate, modulates LFTR specificity, the conjugation of $\left[{ }^{14} \mathrm{C}\right]-$ Leu varied depending on the identity of this residue. In fact, based on the relative activity of LFTR, the residue downstream of $\mathrm{N}_{\mathrm{d} 2}$ (at position 2) could be broadly categorized into three groups (favored, accepted and disfavored residues). While basic residues (Arg and Lys) were the most favored position 2 residue, polar residues (i.e. Ser, Thr, Gln and Asn), Gly, Pro and His were also the accepted. In contrast to these residues, small hydrophobic residues (i.e. Ala, Leu, Ile and Met) were only weakly accepted at position 2 of the substrate, with relative conjugation rates of $\sim 50 \%$ (Supplementary Figure 8). In contrast to these accepted residues, the remaining residues (i.e. acidic, aromatic and Cys) were all disfavored, with acidic residues the most strongly disfavored residue at position 2. Overall, these changes in the level of conjugation (to two sets of different 11-mer peptides bearing an Nt Arg) clearly demonstrate that (for substrates bearing a classic $\mathrm{N}_{\mathrm{d} 2}$ residue, Arg) the identity of the downstream residue does contribute to LFTR activity. These data are also consistent with the idea that the identity of this residue also plays an important role in modulating the specificity of LFTR in the recognition of substrate proteins bearing a non-canonical $\mathrm{N}_{\mathrm{d} 2}$ residue (i.e. Met or Thr). Indeed, the influence of the residue downstream of on LFTR specificity, for protein substrates bearing non-canonical $\mathrm{N}_{\mathrm{d} 2}$ residues, may be greater than that for canonical $\mathrm{N}_{\mathrm{d} 2}$ residues (i.e. Arg and Lys). Furthermore, although His was a permissive residue at position 2 in the context of an Nt Arg, we noted a small but specific difference in the conjugation of $\left[{ }^{14} \mathrm{C}\right]$-Leu to $\mathrm{RH}$-casein in comparison 
exclude that this small difference may be due to the limited sample size of these single use, peptide array experiments, there is remarkable consistency across the remaining 19 amino acids. Therefore, we propose that the residue(s) downstream of position 2 (i.e. position 3 and 4), may also make a minor contribution to LFTR specificity that may be particularly important for LFTR-substrates bearing a non-canonical $\mathrm{N}_{\mathrm{d} 2}$ residue.

424 Therefore, to further examine the role of His (at position 2) in a substrate bearing a non-canonical $425 \mathrm{~N}_{\mathrm{d} 2}$, we monitored the in vitro conjugation of $\left[{ }^{14} \mathrm{C}\right]$-Leu to a selection of recombinant PATase mutant 426 proteins, in which either the $\mathrm{N}$-terminal or the second residue of the protein was altered (Figure 3B 427 upper panel). As expected, the conjugation of $\left[{ }^{14} \mathrm{C}\right]$-Leu was strongest to the positive control 428 acceptor protein (i.e. RN-PATase), which contains a canonical $\mathrm{N}_{\mathrm{d} 2}$ residue followed by an "accepted" position 2 residue (Figure 3B lower panel, lane 7). Similarly, the conjugation of $\left[{ }^{14} \mathrm{C}\right]-\mathrm{Leu}$ (or $\left[{ }^{14} \mathrm{C}\right]-$ 430 Phe) was not observed to the negative control acceptor protein (i.e. FM-PATase), which bears a 431 bulky hydrophobic residue at both the N-terminus and position 2 (Figure 3B lower panel, lane 5 and 432 Supplementary Figure 9). In contrast, weak conjugation of $\left[{ }^{14} \mathrm{C}\right]-\mathrm{Leu}$ (but none of $\left.\left[{ }^{14} \mathrm{C}\right]-\mathrm{Phe}\right)$ was observed for the acceptor FL-PATase (Figure 3B lower panel, lane 4). Although these data are somewhat surprising, they are consistent with the poly-leucylation (conjugation of multiple Leu residues) observed for M-PATase, LM-PATase and LLM-PATase both in vitro and in vivo (Ninnis et al., 2009;Humbard et al., 2013) which demonstrates that although the acceptor pocket of LFTR is able to accommodate two small hydrophobic residues, it is unable to accommodate two large hydrophobic residues. Most importantly, and consistent with a moderating role for position 2 of the acceptor, the conjugation of $\left[{ }^{14} \mathrm{C}\right]$-Leu to PATase, was completely inhibited by its replacement with 440 His (i.e. $\mathrm{MH}_{2}$-PATase) (Figure 3B lower panel, compare lanes 2 and 8). A similar profile was also 441 observed for the conjugation of $\left[{ }^{14} \mathrm{C}\right]$-Phe to the same protein substrates, albeit with a reduced 442 activity (Supplementary Figure 9). Collectively, these data confirm that LFTR-substrates bearing a 443 non-canonical $\mathrm{N}_{\mathrm{d} 2}$ residues (i.e. $\mathrm{M}$ or $\mathrm{T}, \mathrm{L}$ or $\mathrm{F}$ ) are influenced by the identity of the downstream 444 residue, and more specifically that Asn appears to be preferred over His, in the context of a substrate 445 bearing an Nt Met. 
In this study, we used ClpS-affinity chromatography to isolate Leu/N-degron ligands from $\Delta c l p A$ and $\Delta a a t E$. coli cells in stationary phase. Comparison of the dipeptide eluted proteins recovered from $\triangle c l p A$ cells and not from $\triangle a a t$ cells identified eight ligands that are dependent on LFTR activity for their interaction with ClpS (Figure 1). Of these eight LFTR-dependent Leu/N-degron ligands, four (AldB, AccD, SufD and PATase) are degraded by ClpAPS ex vivo, three of which (AldB, AccD and PATase) we confirmed by $\mathrm{N}$-terminal sequencing to contain a non-ribosomal $\mathrm{N}_{\mathrm{d} 1}$ residue (i.e. Leu). In addition to the above proteins, $\mathrm{ClpB}$ and EngS were also identified as potential LFTR-dependent substrates, however as we were unable to determine the N-terminal sequence of these protein or monitor their turnover ex vivo, these proteins remain unverified Leu/ $\mathrm{N}$-degron ligands. In contrast to the above proteins, AccA and SufC are identified as passenger ligands that co-purified with genuine Leu/N-degron ligands (AccD and SufD, respectively). Of the confirmed Leu/N-degron ligands, PATase was previously identified as a LFTR-dependent substrate in which the initiating Met was shown to serve as an $\mathrm{N}_{\mathrm{d} 2}$ residue (Ninnis et al., 2009; Schmidt et al., 2009;Humbard et al., 2013). The three remaining ligands are processed prior to their conjugation by LFTR. For AccD and SufD the processing involves removal of a short N-terminal segment, via an unidentified endopeptidase. While in the case of $\mathrm{AldB}$, removal of the initiating Met by the exopeptidase MetAP is sufficient to generate an LFTR substrate. Unexpectedly, N-terminal sequencing of AldB (eluted from the ClpS affinity column) revealed that the primary destabilizing residue (Leu) is post-translationally attached to Thr2 of AldB. Hence, these data demonstrate that AldB is a novel LFTR-dependent Leu/N-degron ligand, and show that, like the eukaryotic N-degron pathways, MetAP plays a direct role in the bacterial Leu/N-degron pathway (Varshavsky, 2011;Nguyen et al., 2019;Varshavsky, 2019). Importantly, although the LFTR-dependent modification of recombinant $\mathrm{T}_{2}$-AldB was not confirmed, the leucylation of two model proteins (bearing an Nt Thr): i.e. T-PATase and a $\mathrm{T}_{2}-\mathrm{AldB}_{3-11} \mathrm{GFP}$ (Figure 2), was observed in vitro. One explanation for this apparent incongruity is that the N-terminus of recombinant $\mathrm{T}_{2}$-AldB is inaccessible to LFTR in vitro and the modification of $\mathrm{T}_{2}$-AldB in vivo is conditional upon exposure of its N-terminus. Importantly, consistent with the identification of $\mathrm{LT}_{2}$ AldB as an LFTR-dependent Leu/N-degron ligand, LT $_{2}$-AldB is rapidly degraded by ClpAPS in vitro (Figure 2) although we have yet to establish the condition for AldB turnover in vivo. Taken together, our data suggest that $\mathrm{T}_{2}$-AldB is a conditional LFTR-dependent substrate, the modification of which is dependent on exposure of the N-terminus and the identity of the residue in position 2. This conditional recognition is somewhat reminiscent of the Ac/N-degron pathway in mammals, in which Ac/N-degrons only become exposed (and hence degraded) for instance, in the absence of a partner protein (Hwang et al., 2010; Shemorry et al., 2013;Nguyen et al., 2018). Based on our findings, we 
propose a model for the conditional modification and degradation of E. coli AldB (Supplementary Figure 10). In this model, Nt Met excision (by MetAP) is a crucial step in preparing $\mathrm{T}_{2}$-AldB for its conditional modification by LFTR. This modification of $\mathrm{T}_{2}$-AldB generates a Leu/N-degron ligand $\left(\mathrm{LT}_{2}-\mathrm{AldB}\right)$ which is recognized by $\mathrm{ClpS}$ and degraded by ClpAP in vitro. Therefore our findings suggest, that in addition to the basic residues (Arg and Lys) (Tobias et al., 1991) and the initiating Met of PATase (Ninnis et al., 2009), Nt Thr (of AldB) can also act as a $\mathrm{N}_{\mathrm{d} 2}$ residue for conjugation by LFTR (during stationary phase).

What is the function of $E$. coli AldB and why is $\mathrm{T}_{2}$-AldB modified by LFTR? AldB belongs to a group of enzymes (Aldehyde dehydrogenases), that catalyze the oxidation of aldehydes to carboxylic acids. Currently, the function of AldB in E. coli is unclear, however its expression has been linked to persister cell formation (Kawai et al., 2018) and a short-term adaptation response to glucose limiting conditions (Franchini and Egli, 2006). The expression of AldB is also upregulated in response to ethanol stress and upon entry into stationary phase and as such has been proposed to detoxify alcohols and aldehydes that accumulate during stationary phase (Xu and Johnson, 1995;Ho and Weiner, 2005). Interestingly, YiaY (encoded by the gene upstream of aldB) is a putative alcohol dehydrogenase, which together with AldB, contributes to sequential enzymatic steps in the oxidation of ethanol to acetate, via acetaldehyde. Therefore, one possibility is that following recovery from ethanol stress or on exit from stationary phase the cellular levels of AldB (and YiaY) are controlled by the Leu/N-degron pathway. Intriguingly, YiaY is also known to exhibit Threonine dehydrogenase (TDH) activity (Ma et al., 2014), and TDH activity in E. coli was previously proposed to be regulated by LFTR (Newman et al., 1976), Despite this, a definitive link between the metabolic stability of AldB (via its modification by LFTR) and YiaY or a specific cellular stress has yet to be elucidated.

Given the identification of $\mathrm{T}_{2}$-AldB as a substrate of LFTR, we considered the possibility that (under different conditions), MetAP cleavage of other proteins with the Nt sequence MTN, may generate additional LFTR substrates. Therefore, we searched the E. coli genome for sequences encoding proteins with the Nt sequence, MTN. From this analysis we identified 20 proteins (9 of unknown function), in which the Nt sequence (MTN) is located within the cytosol (i.e. cytosolic proteins, single or multi-pass inner membrane proteins). Of these 20 proteins, 12 lacked acidic residue near the $\mathrm{N}$-terminus and hence were selected as potential LFTR-substrates (Supplementary Table 5).

510 Interestingly, six of the proteins are known to be cleaved (at least partially) by MetAP and one 511 protein (BarA) is a known ClpA-interacting protein (Butland et al., 2005;Rajagopala et al., 
2014;Bienvenut et al., 2015) and hence may represent an additional Leu/N-degron substrate in $E$.

513 coli. However, there is currently no direct evidence that any of these proteins are modified by LFTR.

514 Therefore, more work is required to see if the metabolic stability of these proteins (including BarA)

515 is influenced either by ClpS or LFTR.

516 To further examine the acceptor specificity of LFTR we used peptide arrays. This analysis

517 demonstrated that residue(s) downstream of the $\mathrm{N}_{\mathrm{d} 2}$ can influence the specificity of LFTR. Based on

518 our conjugation data, we propose a relative classification (favored, accepted and disfavored) for

519 residues in position 2 of the acceptor. Although the vast majority of residues (e.g. small polar and

520 small hydrophobic residues) are accepted in position 2 of the substrate (> 50\% conjugation, relative

521 to R-b, where $\mathrm{b}=\mathrm{R}$ or K), only basic residues (i.e. Arg and Lys) are strongly favored in this position.

522 In contrast, acidic residues are strongly disfavored in position 2 of the acceptor $(<20 \%$ conjugation,

523 relative to $\mathrm{R}-\mathrm{b}$,), while aromatic residues and Cys are also disfavored $(<30 \%$ conjugation, relative to

524 R-b). Significantly, these direct conjugation data are not only generally consistent with the

525 physicochemical properties of the LFTR binding pocket (Suto et al., 2006; Watanabe et al., 2007), but

526 they are also highly consistent with the findings of Soffer, who examined the ability of select b-X

527 dipeptides (where $\mathrm{b}=$ Arg or Lys and $\mathrm{X}=$ selected amino acids) to inhibit the LFTR-dependent

528 conjugation of $\left[{ }^{14} \mathrm{C}\right]$-Phe to $\alpha_{\mathrm{S} 1}$-casein (Soffer, 1973). Fittingly, the acceptor specificity of LFTR is

529 comparable to the substrate specificity of the two other main components of the bacterial Leu/N-

530 degron pathway, MetAP (Frottin et al., 2006) and the N-recognin, ClpS (Erbse et al., 2006; Wang et

531 al., 2008b;Schuenemann et al., 2009), both of which disfavor acidic residues near the N-terminus of

532 their substrates.

533

534 FIGURE LEGENDS

535 Figure 1. Identification of putative LFTR-dependent N-degron substrates from E. coli.

536 (A) The ex vivo turnover of selected E. coli N-degrons; AldB, AccD and PATase (as a positive 537 control) was monitored using specific antisera, in the presence of ClpAPS (lanes 1 - 5) or 538 ClpAPS $_{\mathrm{DD} / \mathrm{AA}}($ lanes 6 - 10). (B) The ex vivo turnover of putative E. coli N-degrons (SufC and SufD) 539 was monitored using specific antisera, in the presence of ClpAPS (lanes 1 - 5) or ClpAPS 540 (lanes 6 - 10). (C) E. coli proteins from either a $\Delta c l p A$ (lane 2) or $\Delta a a t$ (lane 3) E. coli cell lysate, 541 were applied to Ni-NTA agarose beads containing immobilized wild type (lanes 4 and 6) or mutant 542 (lane 5) ClpS. N-degron proteins were specifically eluted from wild type ClpS (lanes 4 and 6) and not 
543 from the immobilized mutant, $\mathrm{ClpS}_{\mathrm{DD} / \mathrm{AA}}$ (lane 5). LFTR-dependent N-degrons (AldB, AccD and 544 SufD) were only recovered in the FR-eluted fraction from $\Delta c \operatorname{lp} A$ cells (lane 4) and not in the FReluted fraction from $\Delta a a t$ cells (lane 6). Proteins were separated by Tricine SDS-PAGE.

546 Figure 2. The LFTR-dependent leucylation of $\mathbf{T}_{2}$-AldB generates a ClpS-dependent substrate 547 for ClpAP, in vitro.

548 (A) The in vitro turnover of AldB is dependent on the presence of an $\mathrm{N}_{\mathrm{d} 1}$ (Leu). The ClpAP-mediated turnover of recombinant $\mathrm{X}-\mathrm{AldB}$ was monitored in vitro, in the absence (lanes $1-7$ ) or presence (lanes 8 - 14) of ClpS. Only LT $_{2}$-AldB (lower panel) was degraded by ClpAPS, neither $\mathrm{MT}_{2}$-AldB (upper panel) nor $\mathrm{T}_{2}$-AldB (middle panel) were degraded by ClpAP or ClpAPS. (B) Schematic representation of the GFP fusions (upper panel). The turnover of $\mathrm{MT}_{2}-\mathrm{AldB}_{3-11} \mathrm{GFP}$ (red squares), $\mathrm{T}_{2^{-}}$ $\mathrm{AldB}_{3-11} \mathrm{GFP}$ (blue diamonds) and $\mathrm{LT}_{2}-\mathrm{AldB}_{3-11} \mathrm{GFP}$ (black circles) was monitored in the absence (filled symbols) or presence (open symbols) of ClpS. Protein turnover was monitored by the loss of GFP fluorescence $\left(\lambda_{\mathrm{ex}}=400 \mathrm{~nm}\right.$ and $\left.\lambda_{\mathrm{em}}=510 \mathrm{~nm}\right)$. (C) The LFTR-dependent modification of TPATase (lanes 1 and 6), $\mathrm{LT}_{2}-\mathrm{AldB}_{3-11} \mathrm{GFP}$ (lanes 2 and 7), $\mathrm{MT}_{2}-\mathrm{AldB}_{3-11} \mathrm{GFP}$ (lanes 3 and 8 ) and $\mathrm{T}_{2^{-}}$ $\mathrm{AldB}_{3-11}$ GFP (lanes 4 and 9) was monitored in the presence of either $\left[{ }^{14} \mathrm{C}\right]$-Leu (lanes $\left.1-4\right)$ or $\left[{ }^{14} \mathrm{C}\right]-$ Phe (lanes 6 -9). See blue MW markers are indicated.

Figure 3. The specificity of LFTR is influenced by the identity of the residue in position 2.

560 (A, upper panel) $\left[{ }^{14} \mathrm{C}\right]$-Leu phosphorimages of two 11-mer peptide libraries with LFTR highlighting 561 R-X-casein peptide spots (for the full phosphorimage of each library, see Supplementary Figure 6).

562 Peptide sequences for R-X-casein peptides are indicated below each peptide library panel. For details of all other peptide sequences see Supplementary Tables 2 and 3. (A, lower panel) Conjugation of $\left[{ }^{14} \mathrm{C}\right]$-Leu to $\mathrm{R}$-X-casein, relative to the average conjugation of $\mathrm{R}$-b-casein, where $\mathrm{b}=\mathrm{R}, \mathrm{K}$. Relative conjugation activity was determined from two independent experiments and is separated into three broad categories (favored (>75\%), accepted (40 - 75\%, grey panel) and disfavored $(<40 \%)$ ). The Nt leucylation of XX-PATase in vitro is dependent on the identity of the first two residues. Nt sequences of XX-PATase mutants used in the assays (upper panel). Recombinant XX-PATase was separated by $12.5 \%$ SDS-PAGE and stained with Coomassie Brilliant Blue (CBB, lower panel).

570 Following drying of the stained, polyacrylamide gel, the $\left[{ }^{14} \mathrm{C}\right]$-Leu radiolabeled proteins were detected by phosphor image analysis using a Typhoon Trio Variable Mode Imager (panel). As a control MN-PATase was incubated in the presence (lane 2) or absence (lane 3) of LFTR. All other 
XX-PATase variants were incubated in the presence of LFTR. FL-PATase (lane 4), FM-PATase (lane 5) TN-PATase (lane 6) RN-PATase (lane 7) and MH-PATase (lane 9). See blue + MW markers (lane 1).

576

577

578

579

580

581

582

583

584

585

586

\section{AUTHOR CONTRIBUTIONS}

Conceptualization, D.A.D. and K.N.T.; methodology, K.N.T. and D.A.D.; investigation, R.D.O and R.L.N.; writing original draft, R.D.O., D.A.D. and K.N.T.; supervision, project administration and funding acquisition, D.A.D. and K.N.T.

\section{FUNDING}

K.N.T. was supported by and Australian Research Council (A.R.C.) Future Fellowship (FT0992033) and D.A.D. was supported by an A.R.C. Australian Research Fellowship (DP110103936). R.D.O. and R.L.N. were supported by Australian Postgraduate Awards.

\section{ACKNOWLEDGEMENTS}

We thank the Australian Proteome Analysis Facility (APAF) for performing Edman degradation, the National BioResource Project (NIG, Japan) for the E. coli strains used in this study.

\section{REFERENCES}

Alhuwaider, A.H., and Dougan, D.A. (2017). AAA+ Machines of Protein Destruction in Mycobacteria. Front Mol Biosci 4, 49.

Bienvenut, W.V., Giglione, C., and Meinnel, T. (2015). Proteome-wide analysis of the amino terminal status of Escherichia coli proteins at the steady-state and upon deformylation inhibition. Proteomics 15, 2503-2518.

Bouchnak, I., and Van Wijk, K.J. (2019). N-Degron Pathways in Plastids. Trends Plant Sci 24, 917 926.

Butland, G., Peregrin-Alvarez, J.M., Li, J., Yang, W., Yang, X., Canadien, V., et al. (2005). Interaction network containing conserved and essential protein complexes in Escherichia coli. Nature 433, 531-537.

Catanzariti, A.M., Soboleva, T.A., Jans, D.A., Board, P.G., and Baker, R.T. (2004). An efficient system for high-level expression and easy purification of authentic recombinant proteins. Protein Sci 13, 1331-1339.

Chen, S.J., Wu, X., Wadas, B., Oh, J.H., and Varshavsky, A. (2017). An N-end rule pathway that recognizes proline and destroys gluconeogenic enzymes. Science 355.

Dissmeyer, N., Rivas, S., and Graciet, E. (2018). Life and death of proteins after protease cleavage: protein degradation by the N-end rule pathway. New Phytol 218, 929-935.

Dougan, D.A., Micevski, D., and Truscott, K.N. (2012). The N-end rule pathway: from recognition by N-recognins, to destruction by AAA+proteases. Biochim Biophys Acta 1823, 83-91.

Dougan, D.A., Mogk, A., Zeth, K., Turgay, K., and Bukau, B. (2002a). AAA+ proteins and substrate recognition, it all depends on their partner in crime. FEBS Lett 529, 6-10.

This is a provisional file, not the final typeset article 
609

610

611

612

613

614

615

616

617

618

619

620

621

622

623

624

625

626

627

628

629

630

631

632

633

634

635

636

637

638

639

640

641

642

643

644

645

646

647

648

649

650

651

652

653

654

655

Dougan, D.A., Reid, B.G., Horwich, A.L., and Bukau, B. (2002b). ClpS, a substrate modulator of the ClpAP machine. Mol Cell 9, 673-683.

Dougan, D.A., Truscott, K.N., and Zeth, K. (2010). The bacterial N-end rule pathway: expect the unexpected. Mol Microbiol 76, 545-558.

Dougan, D.A., and Varshavsky, A. (2018). Understanding the Pro/N-end rule pathway. Nat Chem Biol 14, 415-416.

Erbse, A., Schmidt, R., Bornemann, T., Schneider-Mergener, J., Mogk, A., Zahn, R., et al. (2006). ClpS is an essential component of the N-end rule pathway in Escherichia coli. Nature 439, 753-756.

Flynn, J.M., Neher, S.B., Kim, Y.I., Sauer, R.T., and Baker, T.A. (2003). Proteomic discovery of cellular substrates of the ClpXP protease reveals five classes of ClpX-recognition signals. Mol Cell 11, 671-683.

Franchini, A.G., and Egli, T. (2006). Global gene expression in Escherichia coli K-12 during shortterm and long-term adaptation to glucose-limited continuous culture conditions. Microbiology (Reading) 152, 2111-2127.

Frottin, F., Martinez, A., Peynot, P., Mitra, S., Holz, R.C., Giglione, C., et al. (2006). The proteomics of N-terminal methionine cleavage. Mol Cell Proteomics 5, 2336-2349.

Gao, X., Yeom, J., and Groisman, E.A. (2019). The expanded specificity and physiological role of a widespread N-degron recognin. Proc Natl Acad Sci U S A 116, 18629-18637.

Geissler, A., Chacinska, A., Truscott, K.N., Wiedemann, N., Brandner, K., Sickmann, A., et al. (2002). The mitochondrial presequence translocase: an essential role of Tim50 in directing preproteins to the import channel. Cell 111, 507-518.

Gibbs, D.J., Bacardit, J., Bachmair, A., and Holdsworth, M.J. (2014). The eukaryotic N-end rule pathway: conserved mechanisms and diverse functions. Trends Cell Biol 24, 603-611.

Graciet, E., Hu, R.G., Piatkov, K., Rhee, J.H., Schwarz, E.M., and Varshavsky, A. (2006). Aminoacyl-transferases and the N-end rule pathway of prokaryotic/eukaryotic specificity in a human pathogen. Proc Natl Acad Sci U S A 103, 3078-3083.

Gur, E., Ottofueling, R., and Dougan, D.A. (2013). Machines of destruction - AAA+ proteases and the adaptors that control them. Subcell Biochem 66, 3-33.

Ho, K.K., and Weiner, H. (2005). Isolation and characterization of an aldehyde dehydrogenase encoded by the aldB gene of Escherichia coli. J Bacteriol 187, 1067-1073.

Humbard, M.A., Surkov, S., De Donatis, G.M., Jenkins, L.M., and Maurizi, M.R. (2013). The Ndegradome of Escherichia coli: limited proteolysis in vivo generates a large pool of proteins bearing N-degrons. J Biol Chem 288, 28913-28924.

Hwang, C.S., Shemorry, A., and Varshavsky, A. (2010). N-terminal acetylation of cellular proteins creates specific degradation signals. Science 327, 973-977.

Kaji, A., Kaji, H., and Novelli, G.D. (1963). A soluble amino acid incorporating system. Biochem Biophys Res Commun 10, 406-409.

Kawai, Y., Matsumoto, S., Ling, Y., Okuda, S., and Tsuneda, S. (2018). AldB controls persister formation in Escherichia coli depending on environmental stress. Microbiol Immunol 62, 299309.

Keiler, K.C., Waller, P.R., and Sauer, R.T. (1996). Role of a peptide tagging system in degradation of proteins synthesized from damaged messenger RNA. Science 271, 990-993.

Kim, H.K., Kim, R.R., Oh, J.H., Cho, H., Varshavsky, A., and Hwang, C.S. (2014). The N-terminal methionine of cellular proteins as a degradation signal. Cell 156, 158-169.

Kirstein, J., Moliere, N., Dougan, D.A., and Turgay, K. (2009). Adapting the machine: adaptor proteins for Hsp100/Clp and AAA+ proteases. Nat Rev Microbiol 7, 589-599. 
656

657

658

659

660

661

662

663

664

665

666

667

668

669

670

671

672

673

674

675

676

677

678

679

680

681

682

683

684

685

686

687

688

689

690

691

692

693

694

695

696

697

698

699

700

701

702

703

704

Kress, W., Mutschler, H., and Weber-Ban, E. (2009). Both ATPase domains of ClpA are critical for processing of stable protein structures. J Biol Chem 284, 31441-31452.

Leibowitz, M.J., and Soffer, R.L. (1970). Enzymatic modification of proteins. 3. Purification and properties of a leucyl, phenylalanyl transfer ribonucleic acid protein transferase from Escherichia coli. J Biol Chem 245, 2066-2073.

Lucas, X., and Ciulli, A. (2017). Recognition of substrate degrons by E3 ubiquitin ligases and modulation by small-molecule mimicry strategies. Curr Opin Struct Biol 44, 101-110.

Ma, F., Wang, T., Ma, X., and Wang, P. (2014). Identification and characterization of protein encoded by orf382 as L-threonine dehydrogenase. J Microbiol Biotechnol 24, 748-755.

Mahmoud, S.A., and Chien, P. (2018). Regulated Proteolysis in Bacteria. Annu Rev Biochem 87, 677-696.

Mogk, A., Schmidt, R., and Bukau, B. (2007). The N-end rule pathway for regulated proteolysis: prokaryotic and eukaryotic strategies. Trends Cell Biol 17, 165-172.

Neuwald, A.F., Aravind, L., Spouge, J.L., and Koonin, E.V. (1999). AAA+: A class of chaperonelike ATPases associated with the assembly, operation, and disassembly of protein complexes. Genome Res 9, 27-43.

Newman, E.B., Kapoor, V., and Potter, R. (1976). Role of L-threonine dehydrogenase in the catabolism of threonine and synthesis of glycine by Escherichia coli. J Bacteriol 126, 12451249.

Nguyen, K.T., Kim, J.M., Park, S.E., and Hwang, C.S. (2019). N-terminal methionine excision of proteins creates tertiary destabilizing N-degrons of the Arg/N-end rule pathway. $J$ Biol Chem 294, 4464-4476.

Nguyen, K.T., Mun, S.H., Lee, C.S., and Hwang, C.S. (2018). Control of protein degradation by Nterminal acetylation and the N-end rule pathway. Exp Mol Med 50, 1-8.

Ninnis, R.L., Spall, S.K., Talbo, G.H., Truscott, K.N., and Dougan, D.A. (2009). Modification of PATase by L/F-transferase generates a ClpS-dependent $\mathrm{N}$-end rule substrate in Escherichia coli. EMBO J 28, 1732-1744.

Ogura, T., and Wilkinson, A.J. (2001). AAA+ superfamily ATPases: common structure--diverse function. Genes Cells 6, 575-597.

Piatkov, K.I., Vu, T.T., Hwang, C.S., and Varshavsky, A. (2015). Formyl-methionine as a degradation signal at the N-termini of bacterial proteins. Microb Cell 2, 376-393.

Rajagopala, S.V., Sikorski, P., Kumar, A., Mosca, R., Vlasblom, J., Arnold, R., et al. (2014). The binary protein-protein interaction landscape of Escherichia coli. Nat Biotechnol 32, 285-290.

Rivera-Rivera, I., Roman-Hernandez, G., Sauer, R.T., and Baker, T.A. (2014). Remodeling of a delivery complex allows ClpS-mediated degradation of N-degron substrates. Proc Natl Acad Sci U S A 111, E3853-3859.

Roman-Hernandez, G., Hou, J.Y., Grant, R.A., Sauer, R.T., and Baker, T.A. (2011). The ClpS adaptor mediates staged delivery of $\mathrm{N}$-end rule substrates to the AAA+ ClpAP protease. $\mathrm{Mol}$ Cell 43, 217-228.

Sauer, R.T., and Baker, T.A. (2011). AAA+ proteases: ATP-fueled machines of protein destruction. Annu Rev Biochem 80, 587-612.

Scarpulla, R.C., Deutch, C.E., and Soffer, R.L. (1976). Transfer of methionyl residues by leucyl, phenylalanyl-tRNA-protein transferase. Biochem Biophys Res Commun 71, 584-589.

Schmidt, R., Zahn, R., Bukau, B., and Mogk, A. (2009). ClpS is the recognition component for Escherichia coli substrates of the N-end rule degradation pathway. Mol Microbiol 72, 506517.

Schuenemann, V.J., Kralik, S.M., Albrecht, R., Spall, S.K., Truscott, K.N., Dougan, D.A., et al. (2009). Structural basis of $\mathrm{N}$-end rule substrate recognition in Escherichia coli by the ClpAP adaptor protein ClpS. EMBO Rep 10, 508-514.

This is a provisional file, not the final typeset article 
705

706

707

708

709

710

711

712

713

714

715

716

717

718

719

720

721

722

723

724

725

726

727

728

729

730

731

732

733

734

735

736

737

738

739

740

741

742

743

744
Shemorry, A., Hwang, C.S., and Varshavsky, A. (2013). Control of protein quality and stoichiometries by N-terminal acetylation and the N-end rule pathway. Mol Cell 50, 540-551.

Shrader, T.E., Tobias, J.W., and Varshavsky, A. (1993). The N-end rule in Escherichia coli: cloning and analysis of the leucyl, phenylalanyl-tRNA-protein transferase gene aat. J Bacteriol 175, 4364-4374.

Soffer, R.L. (1973). Peptide acceptors in the arginine transfer reaction. J Biol Chem 248, 2918-2921.

Striebel, F., Kress, W., and Weber-Ban, E. (2009). Controlled destruction: AAA+ ATPases in protein degradation from bacteria to eukaryotes. Curr Opin Struct Biol 19, 209-217.

Suto, K., Shimizu, Y., Watanabe, K., Ueda, T., Fukai, S., Nureki, O., et al. (2006). Crystal structures of leucyl/phenylalanyl-tRNA-protein transferase and its complex with an aminoacyl-tRNA analog. EMBO J 25, 5942-5950.

Tasaki, T., Sriram, S.M., Park, K.S., and Kwon, Y.T. (2012). The N-end rule pathway. Annu Rev Biochem 81, 261-289.

Timms, R.T., and Koren, I. (2020). Tying up loose ends: the N-degron and C-degron pathways of protein degradation. Biochem Soc Trans 48, 1557-1567.

Tobias, J.W., Shrader, T.E., Rocap, G., and Varshavsky, A. (1991). The N-end rule in bacteria. Science 254, 1374-1377.

Tu, G.F., Reid, G.E., Zhang, J.G., Moritz, R.L., and Simpson, R.J. (1995). C-terminal extension of truncated recombinant proteins in Escherichia coli with a 10Sa RNA decapeptide. $J$ Biol Chem 270, 9322-9326.

Varshavsky, A. (2011). The N-end rule pathway and regulation by proteolysis. Protein Sci 20, 12981345.

Varshavsky, A. (2019). N-degron and C-degron pathways of protein degradation. Proc Natl Acad Sci $U S A$ 116, 358-366.

Wang, K.H., Oakes, E.S., Sauer, R.T., and Baker, T.A. (2008a). Tuning the strength of a bacterial Nend rule degradation signal. J Biol Chem 283, 24600-24607.

Wang, K.H., Roman-Hernandez, G., Grant, R.A., Sauer, R.T., and Baker, T.A. (2008b). The molecular basis of N-end rule recognition. Mol Cell 32, 406-414.

Watanabe, K., Toh, Y., Suto, K., Shimizu, Y., Oka, N., Wada, T., et al. (2007). Protein-based peptide-bond formation by aminoacyl-tRNA protein transferase. Nature 449, 867-871.

$\mathrm{Xu}$, J., and Johnson, R.C. (1995). aldB, an RpoS-dependent gene in Escherichia coli encoding an aldehyde dehydrogenase that is repressed by Fis and activated by Crp. J Bacteriol 177, 31663175 .

Yang, C.I., Hsieh, H.H., and Shan, S.O. (2019). Timing and specificity of cotranslational nascent protein modification in bacteria. Proc Natl Acad Sci U S A 116, 23050-23060.

Yeom, J., and Groisman, E.A. (2019). Activator of one protease transforms into inhibitor of another in response to nutritional signals. Genes Dev 33, 1280-1292.

Yeom, J., Wayne, K.J., and Groisman, E.A. (2017). Sequestration from Protease Adaptor Confers Differential Stability to Protease Substrate. Mol Cell 66, 234-246 e235. 
A

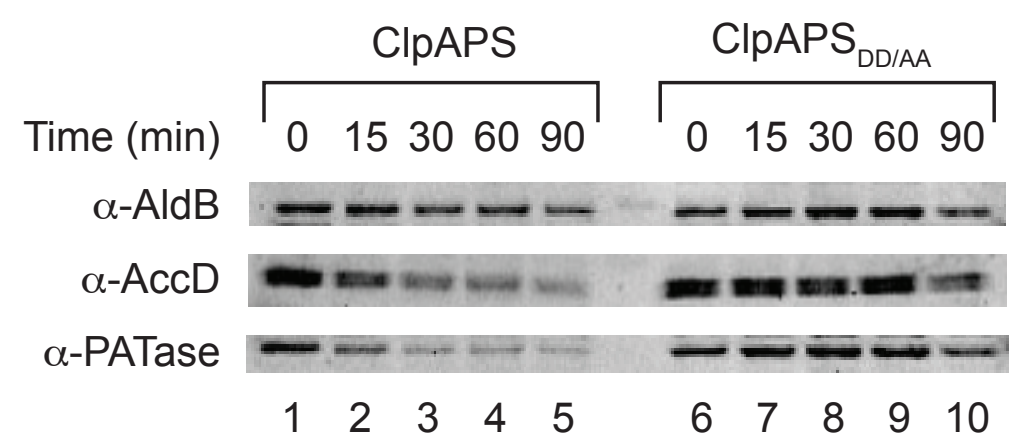

B

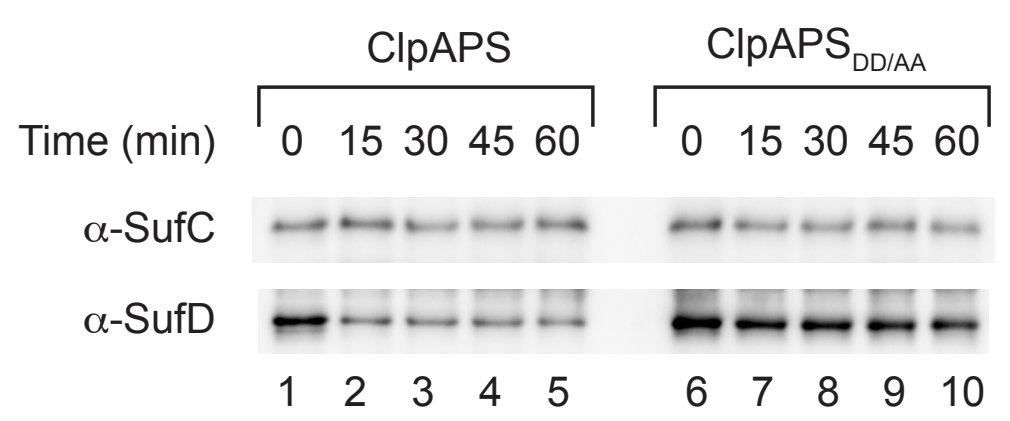

C

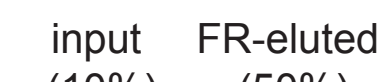

(10\%) (50\%)

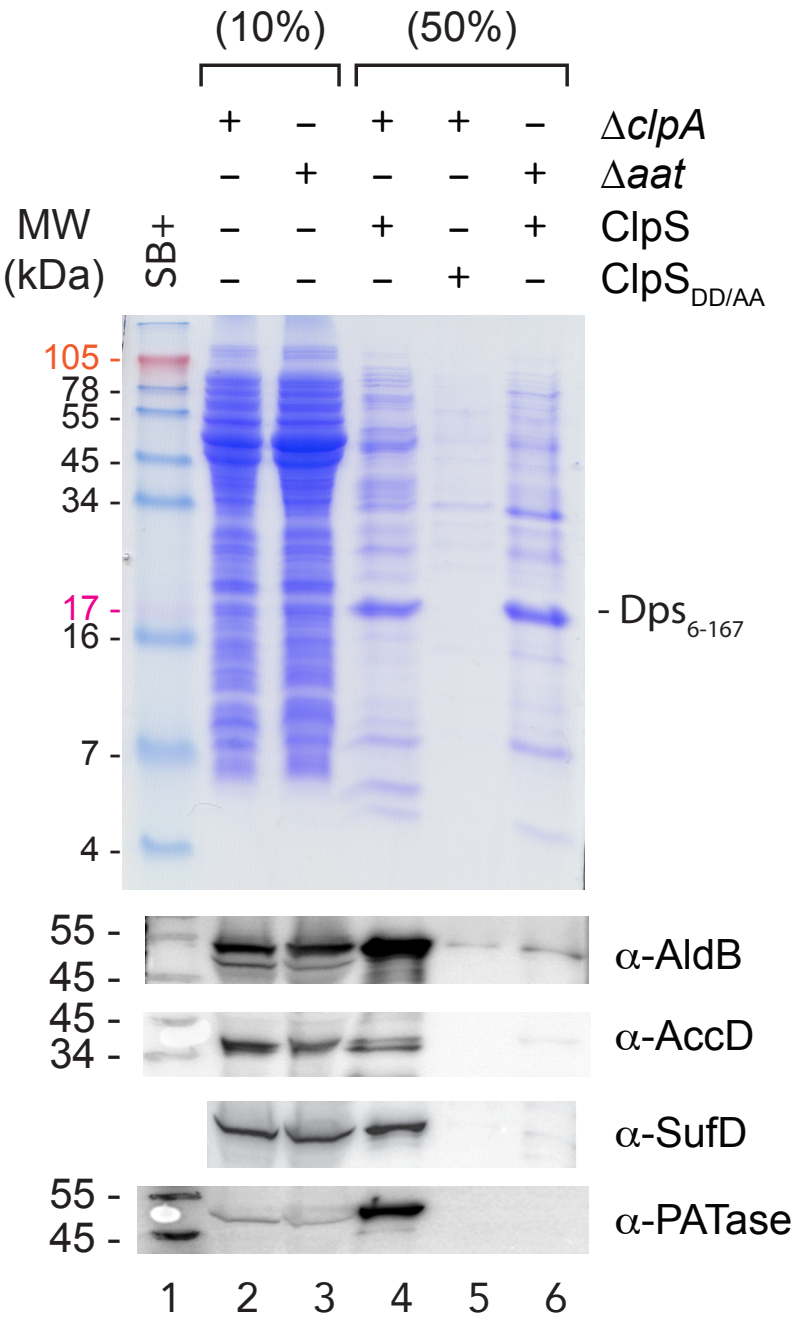

Figure 1 
A

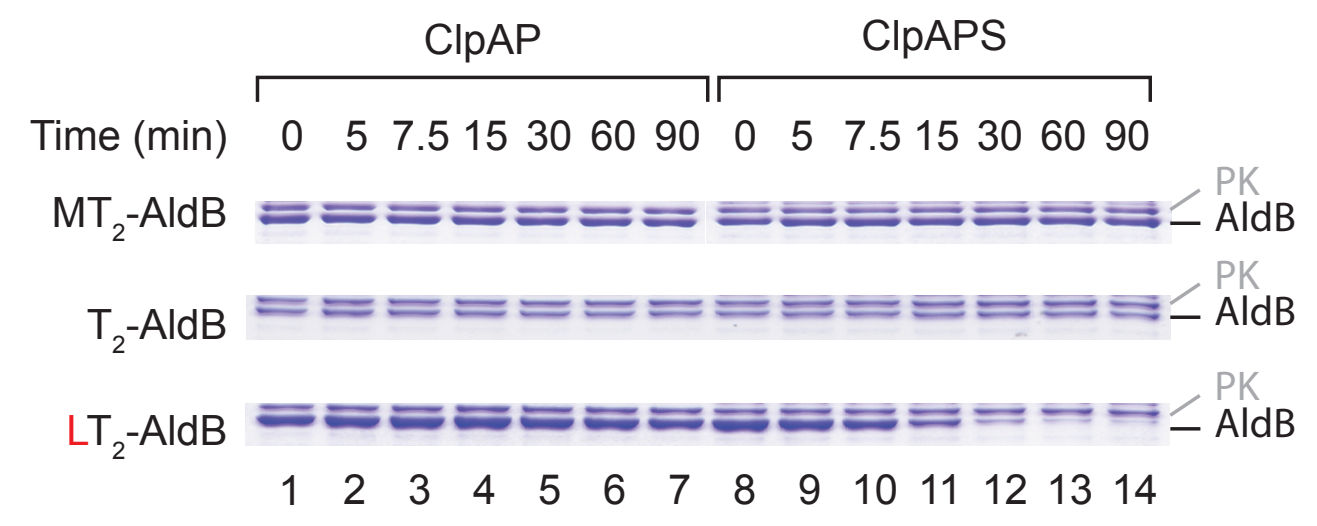

B
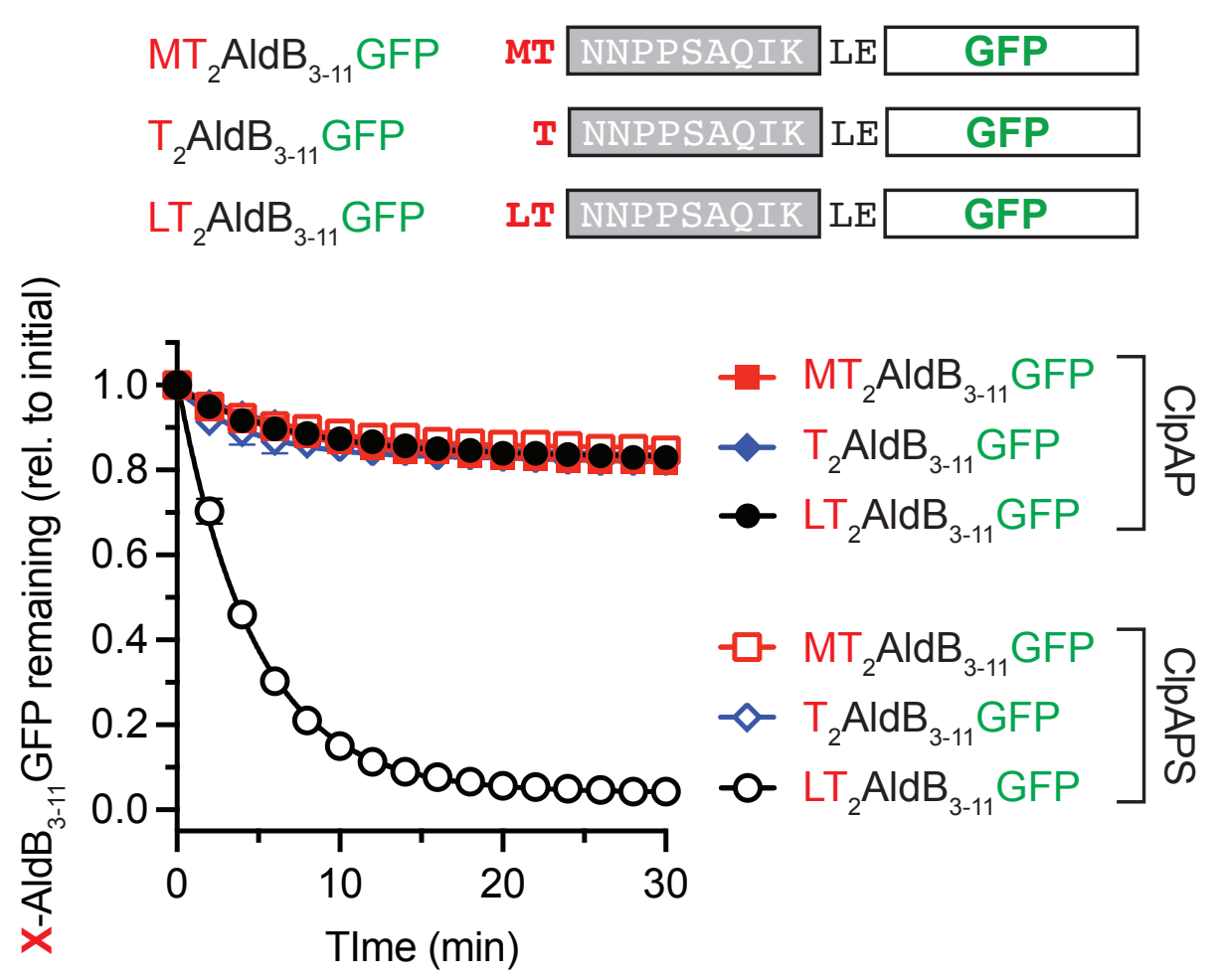

C

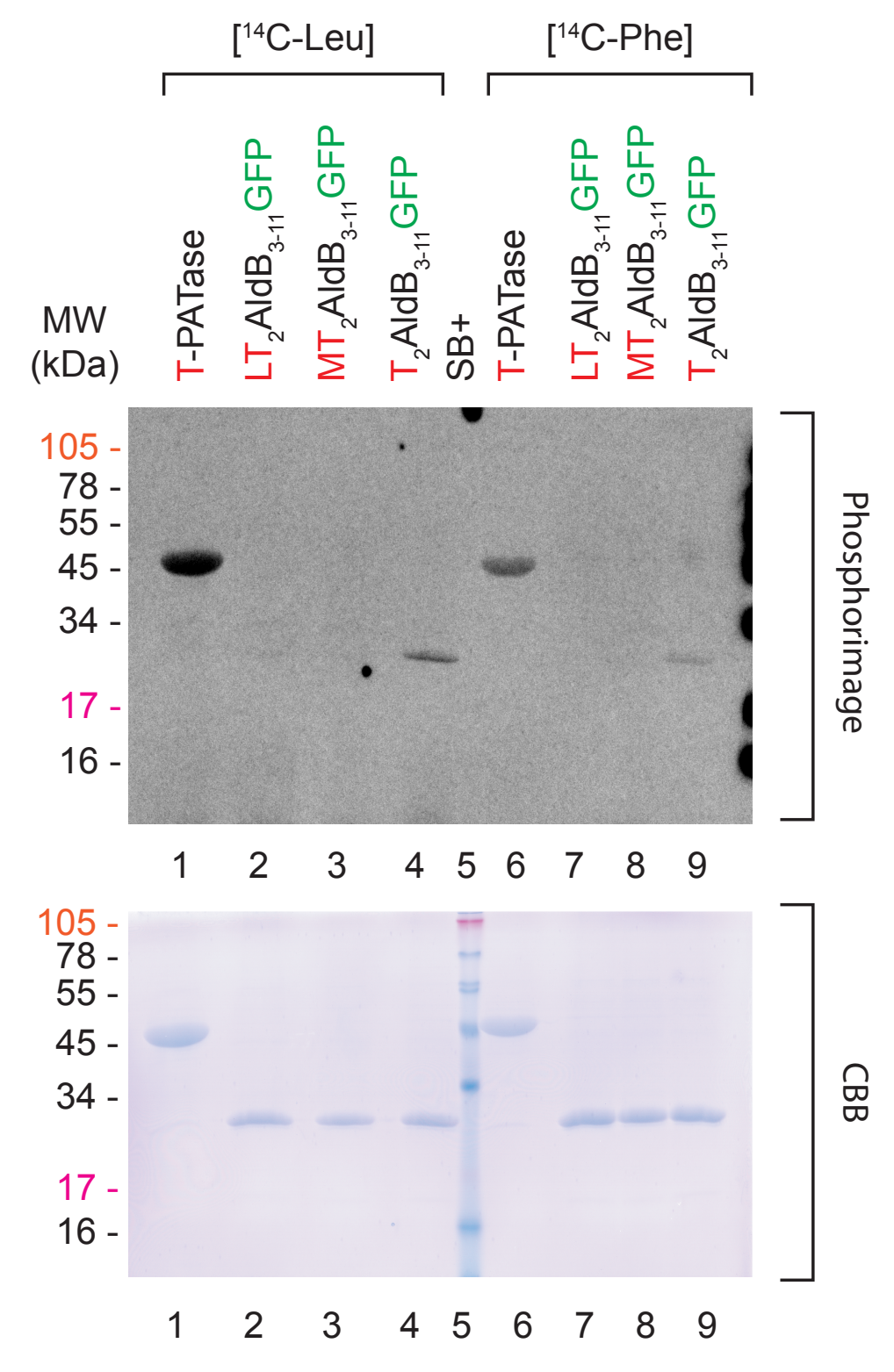

Figure 2 
A

RXLGYLAGSA (R-X-casein)

A V I I M F Y W S T N Q D E R K H C G P

A-61

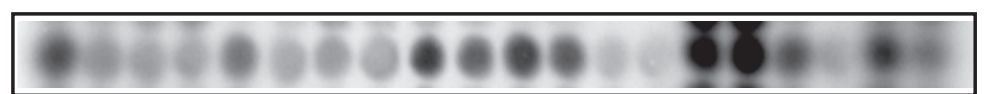

RXLGYLAGSAG ( R-X-casein)

V W Y A C D E F G H I K L M N P Q R S T

61

81
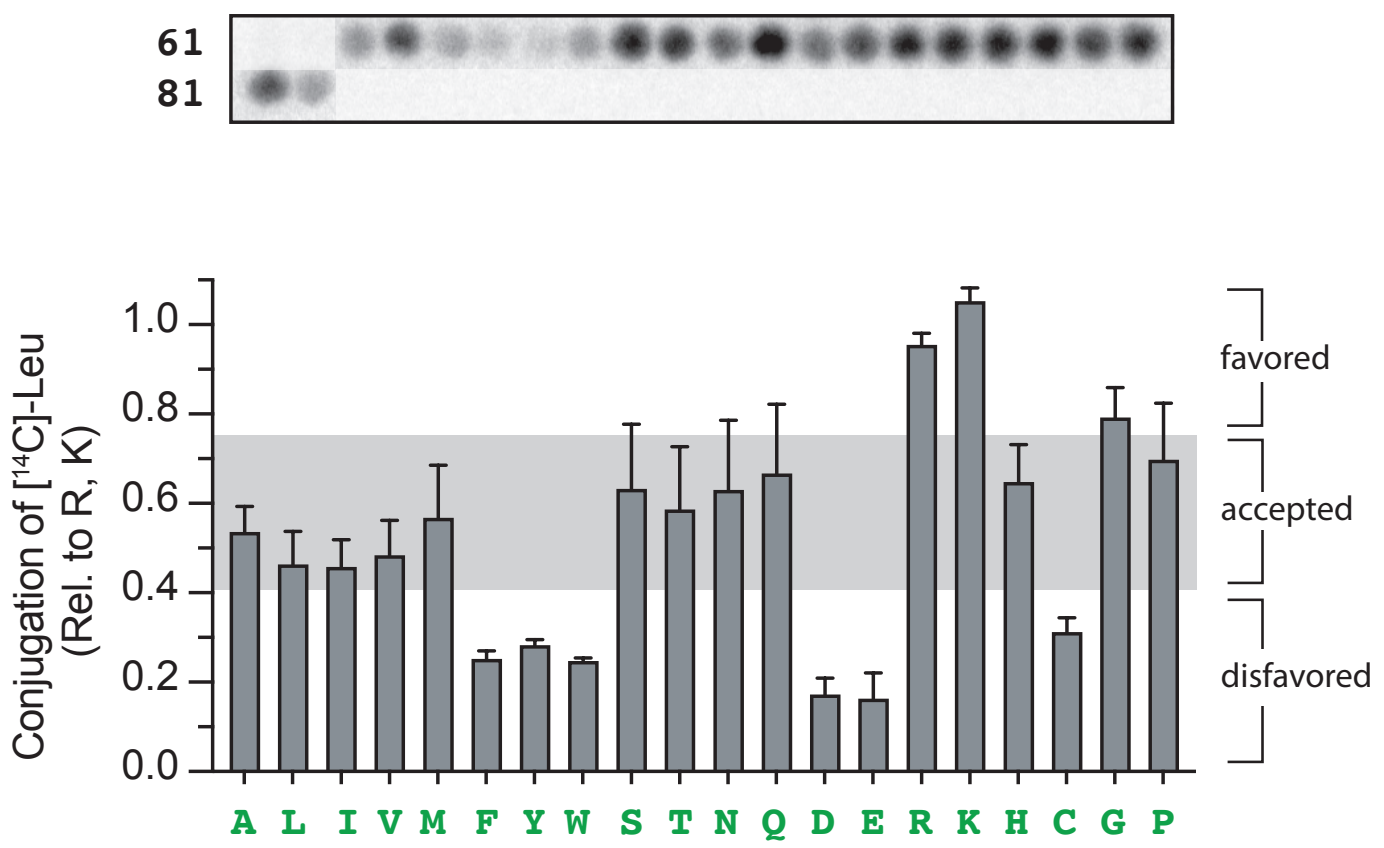

B

$\mathrm{T}_{2}$ AldB

PATase (MN-PATase)

FL-PATase

FM-PATase

TN-PATase

RN-PATase

MH-PATase

1.

10

T NNP P S A O I K

MNRLPS S A A

F L NRLP S S A L

F MNRL P S S A L

T NRLPS S A L A

RNRLPS S L A

MHRL P S S A LA

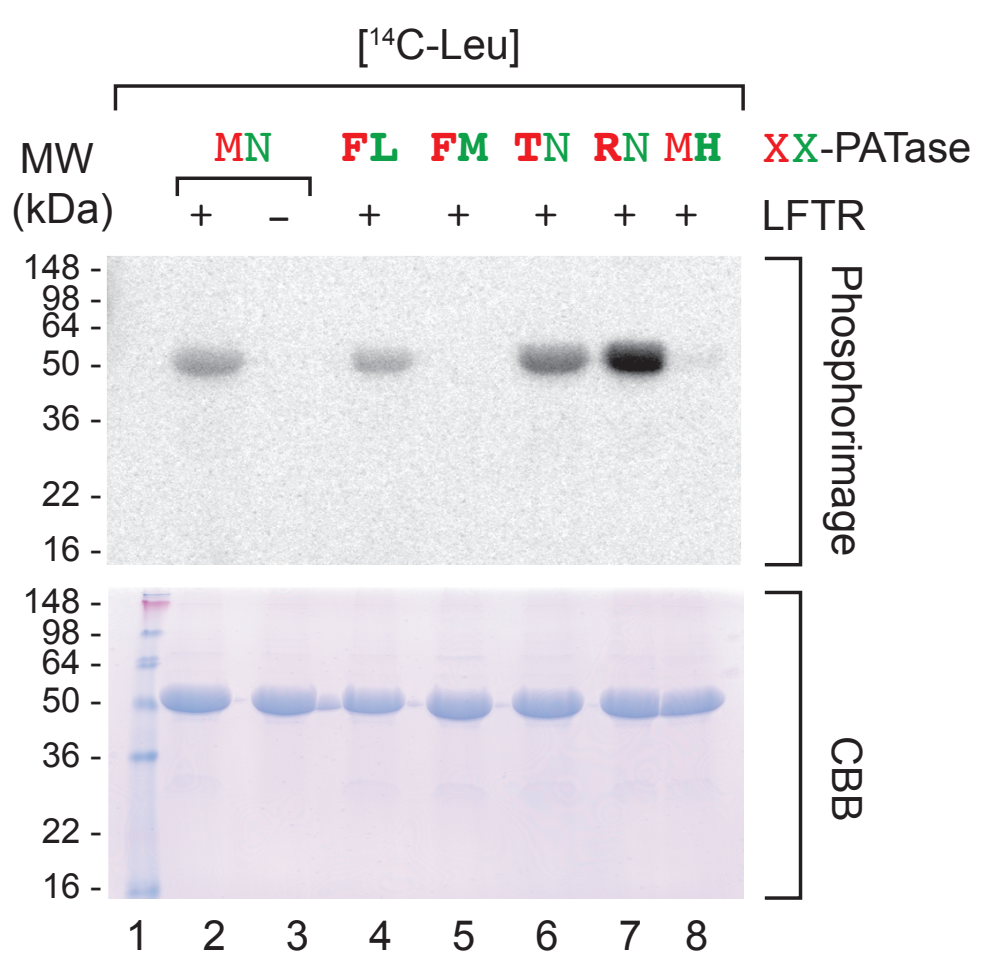

Figure 3 